
linhagens de pimenta do tipo Jalapeño amarelo. Horticultura Brasileira 32: 35-40.

\title{
Caracterização molecular de linhagens de pimenta do tipo Jalapeño amarelo
}

\author{
Arlysson B Ulhoa'; Telma N Pereira'; Raimundo N Silva' ${ }^{1}$; Carlos F Ragassi²; Rosana Rodrigues ${ }^{1}$; Messias \\ G Pereira $^{1}$; Francisco JB Reifschneider ${ }^{2}$ \\ ${ }^{1}$ UENF, CCTA, Av. Alberto Lamego, 2000, Pq. Califórnia, 28013-602 Campos dos Goytacazes-RJ; arlyssonulhoa@gmail.com; \\ telmasp2012@gmail.com; j_raio133@gmail.com; anadigues@gmail.com; messias@uenf.br; ${ }^{2}$ Embrapa Sede, Pq. Estação Biológica, W3 \\ Norte, 70770-901 Brasilia-DF; francisco.reifschneider@embrapa.br; carlos.ragassi@embrapa.br
}

\begin{abstract}
RESUMO
A variabilidade genética no gênero Capsicum é ampla, tanto nas características quantitativas como nas qualitativas. $\mathrm{O}$ mercado de pimentas tem expressiva importância socioeconômica devido ao grande número de agricultores familiares que as cultivam. A pimenta do tipo Jalapeño tem tido uma crescente demanda nos últimos anos pela grande quantidade de polpa que essa pimenta pode produzir, característica importante para a produção de molhos de pimenta. Vinte e quatro linhagens $\mathrm{S}_{4}$ de pimenta Jalapeño amarelo do programa de melhoramento da Embrapa Hortaliças, e duas testemunhas oriundas do Banco de Germoplasma da Universidade Estadual Norte Fluminense Darcy Ribeiro (UENF) foram submetidas à análise molecular com marcadores SSR com o objetivo de estudar a variabilidade genética entre e dentro dessas linhagens. Foram utilizados 63 iniciadores (primers) na triagem inicial e destes, somente 15 confirmaram polimorfismo. O conteúdo de informação polimórfica (PIC) médio para os 15 iniciadores foi de $85 \%$ e destes, onze apresentaram PIC acima da média. A partir do padrão de bandas obtidas, foi possível verificar que as 24 linhagens se encontram em homozigose e que há diferença entre estas.
\end{abstract}

Palavras-chave: Capsicum annuum var. annuum, extração de DNA, microssatélite.

\begin{abstract}
Molecular characterization of inbred lines of yellow Jalapeño pepper

The genetic variability found in the genus Capsicum is broad, both in quantitative as well as in qualitative traits. In Brazil, the hot pepper market has expressive socioeconomic relevance due to the high number of small farmers involved in the production of different pepper types. An increase in the demand of Jalapeño peppers has been observed in the past years due to the thick pulp produced, a trait of interest in the production of hot pepper sauces. Twenty-four $\mathrm{S}_{4}$ yellow Jalapeño inbred lines from the Capsicum breeding program at Embrapa Vegetables and two controls from the Universidade Estadual Norte Fluminense Darcy Ribeiro (UENF) germplasm bank were analyzed with SSR markers with the objective of studying the genetic variability within and among the inbred lines. Sixty-three primers were used for the initial trial and fifteen of these detected polymorphism. Average polymorphic information content (PIC) for the fifteen primers was $85 \%$ and out of these, eleven had PIC above the average. The band pattern indicated that the 24 lines are highly homozygous and that there is variability between them.
\end{abstract}

Keywords: Capsicum annuum var. annuum, DNA extraction, microsatellite.

(Recebido para publicação em 21 de agosto de 2013; aceito em 20 de janeiro de 2014)

(Received on August 21, 2013; accepted on January 20, 2014)

\begin{abstract}
A diversidade genética do gênero Capsicum é grande especialmente quanto à cor, forma, textura, tamanho de fruto, aroma, e até mesmo o grau de pungência (picância ou ardência). Esse gênero abriga as pimentas e pimentões, sendo este último a forma mais cultivada do gênero. Entretanto, o mercado de pimentas é muito segmentado e diversificado, devido à quantidade de subprodutos que podem ser produzidos. $\mathrm{O}$ agronegócio das pimentas possui grande importância socioeconômica, pois envolve desde agricultura familiar (pequenas propriedades) até agroindústrias pequenas (artesanais), médias e multinacionais.
\end{abstract}

Há grande variabilidade de formas botânicas na espécie Capsicum annuum, pois a mesma reúne os pimentões e pimentas doces e picantes $(C$. annuиm var. annuит) $\mathrm{e}$ as pimentas ornamentais $(C$. annuum var. glabriusculum). As flores dessa espécie são muito uniformes, enquanto os frutos podem ser extremamente diferentes quanto ao formato, ao tamanho, à posição na planta, à cor e à pungência (Carvalho et al., 2006). Uma característica marcante desse gênero é a cor dos frutos que em pimentão pode variar do vermelho intenso ao branco. A cor do fruto maduro é controlada por três pares de genes independentes, $\mathrm{y}, \mathrm{c}_{1}$, e $\mathrm{c}_{2}$, sendo, portanto, esperado oito cores diferentes em frutos maduros: vermelho intenso, vermelho claro, laranja, laranja pálido, amarelo-alaranjado, amarelo-alaranjado pálido, amarelo esverdeado e branco (Hurtado-Hernadez \& Smith, 1985).

Dentre as pimentas dessa espécie destaca-se a Jalapeño, que apresenta uma ampla variabilidade. É a pimenta mais popular da América do Norte, sendo considerada uma das melhores pimentas para a produção de molhos, além de proporcionar plantas com alta produtividade. Os frutos da pimenta Jalapeño apresentam tamanhos que variam de 5 a $8 \mathrm{~cm}$ de comprimento e 2,5 a 3 cm de largura; a coloração varia de verde claro a verde escuro quando imaturos, passando a vermelho quando maduros. As paredes dos frutos são espessas, com 
estrias evidentes na epiderme. Seus frutos geralmente apresentam formas cônicas, com pungência média e aroma acentuado, sendo consumidos na forma fresca, desidratada ou em pó. Os frutos apresentam espessura de polpa diferenciada das demais espécies de pimenta, o que proporciona maior volume de polpa (Carvalho et al., 2006), sendo esta a razão da demanda por esse tipo de pimenta ter aumentado.

Em um programa de melhoramento de pimentas da Embrapa Hortaliças detectou-se na cultivar comercial Jalapeño Plus $F_{1}$ três plantas com frutos de coloração amarela, as quais se diferenciavam das demais que apresentavam frutos com coloração vermelha. Desses materiais, três frutos foram coletados, sendo um de cada uma das três plantas. Considerando que a cor do fruto é uma característica complexa e que no decorrer do avanço das gerações houve a segregação de frutos com cor vermelha e cor amarela, esse trabalho teve por objetivo utilizar marcadores moleculares microssatélites (SSR) para avaliar 24 possíveis linhagens de Jalapeño amarelo, oriundos do Banco de germoplasma da Embrapa Hortaliças em Brasília.

\section{MATERIAL E MÉTODOS}

Material genético - Vinte e quatro linhagens $\mathrm{S}_{4}$ de pimenta do tipo Jalapeño amarelo foram utilizadas neste estudo, e como controle foram utilizados os acessos UENF 1381 (C. annuum) e UENF 1775 (C. frustecens), ambos do Banco de Germoplasma da Universidade Estadual Norte Fluminense Darcy Ribeiro (UENF). As plantas que geraram essas linhagens foram selecionadas em um ensaio de avaliação de cultivares de pimenta Jalapeño no campo experimental da Embrapa Hortaliças. Em uma das cultivares do ensaio (Jalapeño Plus $\mathrm{F}_{1}$ ), cujos frutos eram de coloração vermelha quando maduros, foram encontradas três plantas com frutos de coloração amarela, sendo colhido um fruto de cada uma das respectivas plantas que apresentavam essa característica.

Os três frutos tiveram suas sementes extraídas e beneficiadas individualmente de acordo com a RAS (Regra de Análise de Sementes), colocadas para germinar, e cultivadas em casa de vegetação. As plantas oriundas dessas sementes foram conduzidas via método SSD (Single Seed Descent) por três gerações totalizando no final 24 linhagens $\mathrm{S}_{4}$ todos com frutos de coloração amarela.

Extração de DNA - Para obtenção de material para coleta das amostras de DNA, foram semeadas três sementes de cada linhagem em bandejas de poliestireno expandido com 72 células, com substrato Plantmax ${ }^{\circledR}$ e mantidas em casa de vegetação. Quando as plântulas apresentaram cinco folhas, foram retiradas duas a três folhas de cada linhagem para realizar a extração do DNA. A extração foi realizada de acordo com o protocolo descrito pela Embrapa SPI/Cenargen (Brasileiro et al., 1998).

Aproximadamente $0,1 \mathrm{~g}$ de amostra das folhas coletadas foram acondicionadas em um tubo de $2 \mathrm{~mL}$, onde foram adicionados cinco baed's (pequenas esferas) seguido de $750 \mu \mathrm{L}$ de brometo de cetil-trimetilamônio (CTAB) mais $\beta$-mercaptoetanol $(0,2 \%)$. As amostras foram levadas ao equipamento Precellys 24 com a programação 2 (2:5000 - 2x30 - 005) no qual ocorreu a maceração com o auxílio dos bead's. Em seguida os tubos foram submetidos ao banho-maria $\left(65^{\circ} \mathrm{C}\right)$ por 5 minutos e logo após foram adicionados $750 \mu \mathrm{L}$ de clorofil. As amostras foram agitadas em vortex por 1 minuto, visando sua homogeneização. Em seguida foram centrifugadas por 10 minutos, à rotação de $9.000 \mathrm{rpm}$. As fases foram separadas, e então subtraiu-se $600 \mu \mathrm{L}$ do sobrenadante que foram transpostos para um tubo de $1,5 \mathrm{~mL}$, onde se adicionou $400 \mu \mathrm{L}$ de isopropanol. As amostras ficaram em repouso por 10 minutos para que ocorresse a precipitação e logo após foram centrifugadas em rotação máxima (13.000 rpm) por 10 minutos. Posteriormente, o líquido foi vertido permanecendo apenas o pellet (DNA) e adicionados $400 \mu \mathrm{L}$ de etanol gelado. As amostras forma centrifugadas por 10 minutos em rotação máxima, quando se realizou o descarte do etanol permanecendo o pellet. O tubo ficou por 2 horas à temperatura ambiente para a secagem do pellet. Ao final do processo, foi realizada a ressuspensão do pellet utilizando $300 \mu \mathrm{L}$ de água milli- $Q$ (água pura), obtendo-se uma amostra de 300 $\mu \mathrm{L}$ do DNA, de cada um dos 24 acessos de Jalapeño amarelo.

Posteriormente, foi realizada a leitura do volume de DNA de cada material genético com auxílio do equipamento NanoDrop 2000c no qual utilizou-se uma amostra de $0,2 \mu \mathrm{L}$ de cada genótipo (Tabela 1). O DNA foi diluído para a concentração de $5 \mathrm{ng} / \mu \mathrm{L}$ em $100 \mu \mathrm{L}$.

Foram selecionados preliminarmente na literatura 63 microssatélites (SSR). Esses iniciadores (primers) foram desenhados tanto para a espécie Solanum lycopersicum quanto para Capsicum (Sanwen et al., 2000; Lee et al., 2004; Minamiyama et al., 2006). A seleção de primers para tomates foi levada em consideração visto que estes são pertencentes à mesma família das pimentas (Solanaceae).

Reações Polymerase Chain Reaction (PCR-SSR) - Foram realizadas em placa de PCR de 96 poços para termocicladores, com volume final de $13 \mu \mathrm{L}$ contendo $1,5 \mu \mathrm{L}$ de $10 \times$ PCR Buffer, 1,5 $\mu \mathrm{L}$ de DNTPs, 1,0 $\mu \mathrm{L}$ de $\mathrm{MgCl}_{2}, 0,6 \mu \mathrm{L}$ de primer (Forward e Reverse), 0,12 $\mu \mathrm{L}$ de Taq DNA Polimerase, $2,0 \mu \mathrm{L}$ de DNA e $6,28 \mu \mathrm{L}$ de $\mathrm{H}_{2} \mathrm{O}$. As amplificações foram realizadas em termociclador Applied Biosystems Veriti 96 Well, programado em uma etapa inicial de desnaturação do DNA a $94^{\circ} \mathrm{C}$ por 4 minutos, seguido de 38 ciclos de 1 minuto a $94^{\circ} \mathrm{C}$ (desnaturação), 1 minuto nas temperaturas que variaram de $51^{\circ}$, $55^{\circ}, 58^{\circ}$ e $60^{\circ} \mathrm{C}$ (anelamento), de acordo com o primer, e 3 minutos a $72^{\circ} \mathrm{C}$ (extensão) e na etapa final foi programado 7 minutos a $72^{\circ} \mathrm{C}$.

Para separação dos fragmentos foi utilizada uma placa de PCR de 96 poços para sequenciadores com bordas inteiras. Na placa foi adicionado $1 \mu \mathrm{L}$ das reações de PCR e $79 \mu \mathrm{L}$ de água pura, totalizando $80 \mu \mathrm{L}$ de amostra, e em um dos poços da placa foi adicionado o Ladder (determinador do tamanho dos pares de bases). Essa amostra foi utilizada para a realização da leitura por meio de eletroforese capilar.

Os fragmentos amplificados foram separados através do equipamento AdvanCE FS96. A separação das bandas é realizada através de Amplitude Gama, com sistema gel, apropriada para o tamanho dos fragmentos de DNA. Ves- 
tígios electroferograma digitais foram recolhidos por monitorização da intensidade relativa de fluorescência (RFU), de acordo com o tempo de migração das bandas (peso molecular). O marcador $1 \mathrm{~Kb}$ Plus DNA ladder foi utilizado como referência de peso molecular para estimar os tamanhos dos produtos da amplificação.

Foram estimados o conteúdo médio de informação polimórfica (PIC) de cada marcador, a heterozigosidade esperada (He), a heterozigosidade observada (Ho) e o coeficiente médio de endogamia (f) utilizando o software PowerMarker, versão 3.25 (Liu, 2004). A distância genética entre os materias foi estimada utilizando como base a distância de Shared Allele (Liu, 2004).

Com base na matriz de distância ge-

Tabela 1. Leitura do volume de DNA de cada genótipo realizado com o equipamento NanoDrop 2000c (DNA volume per genotype determined with NanoDrop 2000c spectrophotometer). Campos dos Goytacazes, UENF, 2012.

\begin{tabular}{lccc}
\hline & $\begin{array}{c}\text { Concentração de } \\
\text { ácido nucleico }\end{array}$ & $\begin{array}{c}\text { Quantidade de } \\
\text { DNA }\end{array}$ & $\begin{array}{c}\text { Quantidade de } \\
\text { água }\end{array}$ \\
\cline { 2 - 4 } & & $\mathbf{( n g / \mu \mathbf { L } )}$ & \\
\hline 25.237 & 235,9 & 2,12 & 97,88 \\
25.240 & 328,6 & 1,52 & 98,48 \\
25.241 & 268,6 & 1,86 & 98,14 \\
25.242 & 116,7 & 4,28 & 95,72 \\
25.243 & 190,8 & 2,62 & 97,38 \\
25.244 & 218,9 & 2,28 & 97,72 \\
25.245 & 355,1 & 1,41 & 98,59 \\
25.246 & 304,9 & 1,64 & 98,36 \\
25.247 & 259,9 & 1,92 & 98,08 \\
25.248 & 242,5 & 2,06 & 97,94 \\
25.249 & 245,3 & 2,04 & 97,96 \\
25.250 & 314,2 & 1,59 & 98,41 \\
25.252 & 323,8 & 1,54 & 98,46 \\
25.253 & 239,8 & 2,09 & 97,91 \\
25.254 & 235,9 & 2,12 & 97,88 \\
25.255 & 177,2 & 2,82 & 97,18 \\
25.256 & 228,9 & 2,18 & 97,82 \\
25.257 & 158,5 & 3,15 & 96,85 \\
25.259 & 315,2 & 1,59 & 98,41 \\
25.260 & 227,3 & 2,20 & 97,80 \\
25.261 & 190,3 & 2,63 & 97,37 \\
25.262 & 257,9 & 1,94 & 96,46 \\
25.263 & 141,4 & 3,54 & \\
25.265 & 220,1 & 27 & \\
\hline & & & \\
\hline
\end{tabular}

analisar as linhagens de Jalapeño amarelo. Os locos SSR, as sequências forward, reverse, o motif e as temperaturas de anelamento estão apresentados na Tabela 2. Sanwen et al. (2000), em estudo com pimentão (Capsicum annuum), observaram que $12 \mathrm{SSR}$ eram polimórficos e, segundo esses autores, esse número baixo de locos SSR polimórficos se deveu, provavelmente ao tipo de germoplasma utilizado no estudo, em que dos oitos genótipos estudados, quatro eram linhas isogênicas (NIL), ou seja, apresentavam pouco polimorfismo. Kwon et al. (2005), investigando a aplicação dos SSR na análise da distinguibilidade, homogeneidade, e estabilidade (DHE) em 66 variedades de pimentão, observaram que de 316 SSR testados apenas 27 foram polimórficos. A variabilidade genética de 41 acessos de Capsicum, pertencentes à coleção de germoplasma do Crop Research Institute de Praga, foi avaliada utilizando oito locos SSR sendo que apenas cinco foram polimórficos (Hanácek et al., 2009). Assim, os resultados encontrados neste trabalho estão de acordo com o que a literatura tem reportado para Capsicum.

O número médio de alelos por loco foi 12,5 com uma variação de 6 (CA515649) a 23 (CAMS 117) (Tabela $3)$. Esse resultado está acima do que tem sido reportado por outros autores como Minamiyama et al. (2006), Kwon et al. (2005) e Hanácek et al. (2009) que observaram em média 3,23 alelos por loco polimórfico $(2,9 ; 3,29$; e 3,5 respectivamente).

O Conteúdo de Informação Polimórfica (PIC), descrito por Botstein et al. (1980) é um indicador da qualidade do marcador em estudos genéticos (segregação, identificação de populações e controle de paternidade). Segundo a classificação de Botstein et al. (1980), marcadores com valores de PIC superiores a 0,5 são considerados muito informativos, com valores entre 0,25 e 0,50 mediamente informativos, e com valores inferiores a 0,25 , pouco informativos. $\mathrm{O}$ conteúdo de informações de polimorfismo (PIC) encontrado nos 15 primers utilizados nesse trabalho variou de 0,75 (75\%; primer CA515649) a 0,94 (94\%; primer CAMS 117). A média geral entre os 15 iniciadores utilizados foi de $85 \%$ 
Tabela 2. Locos microssatélites (SSR), iniciadores (primers) forward e reverse, motif e temperatura de anelamento (TA) (SSR loci, forward and reverse primers, motif sequences and annealing temperature). Campos dos Goytacazes, UENF, 2012.

\begin{tabular}{|c|c|c|c|c|}
\hline SSR & Sequência forward & Iniciador Reverse & Motif & TA \\
\hline CAMS $024^{1}$ & tgttgaggcttgggaaaaac & caagataatgggtagaaaggcaac & $(\operatorname{tg}) 14 \operatorname{tt}(\operatorname{tg}) 3$ & $55^{\circ} \mathrm{C}$ \\
\hline CAMS $117^{1}$ & ttgtggaggaaacaagcaaa & cctcagcccaggagacataa & $(\operatorname{tg}) 21(\mathrm{ta}) 3$ & $55^{\circ} \mathrm{C}$ \\
\hline CAMS $191^{1}$ & cccgaatccaagtcattgag & taaatccggttccetttcct & (ac) $10 \mathrm{a}(\mathrm{ta}) 4$ & $55^{\circ} \mathrm{C}$ \\
\hline CAMS 207-21 & ctcacgagccacttgaacac & gccttgtttcctatcccaac & (ac)4at(ac)8(at)3 & $55^{\circ} \mathrm{C}$ \\
\hline CAMS $358^{1}$ & gaccettctcccetttttctt & cacatggacggatccttttt & $(\operatorname{tg}) 7$ & $55^{\circ} \mathrm{C}$ \\
\hline CAMS $309^{1}$ & gaaaatcgacccgttttgaa & tcaattcggacaaaattagcaa & (ga)12 & $51^{\circ} \mathrm{C}$ \\
\hline CACCEL $1 i^{2}$ & ctctaataggcaatagctcacatgc & gcagtctcccagaacgttgtcc & (at) 16 & $51^{\circ} \mathrm{C}$ \\
\hline SLM6 $49^{3}$ & attgatggattggcgttctc & aaaatcaggggtgaatttaacg & (ta) 24 & $51^{\circ} \mathrm{C}$ \\
\hline $\mathrm{CM} 0011^{2}$ & tctgctttaaaaacacatacat & cattcttaactgaaattgcatg & (ac) $5(\mathrm{ta}) 8$ & $51^{\circ} \mathrm{C}$ \\
\hline CA $514272^{5}$ & atctattttcctccggegac & cggtaagctgecttgatctc & $(\operatorname{ccg}) 6$ & $51^{\circ} \mathrm{C}$ \\
\hline CA $847580^{5}$ & ggttttctcacaacttcggc & ttgcaaaatatatcaacgcg & $(\operatorname{tg}) 13(\mathrm{ta}) 4$ & $55^{\circ} \mathrm{C}$ \\
\hline CA $523715^{5}$ & catcatttctccccaattcc & gtggtgggtggggtaaaaag & $(\mathrm{tc}) 6(\mathrm{t}) 8$ & $55^{\circ} \mathrm{C}$ \\
\hline CA $515649^{5}$ & tctccaatttccattcggag & taatcgcatttgcgaacttg & (cat) 6 & $58^{\circ} \mathrm{C}$ \\
\hline CM $0008^{4}$ & atagctcacatgccctataaa & aatcttgagcaataattggac & (atata) 5 & $60^{\circ} \mathrm{C}$ \\
\hline $\mathrm{CM} 0005^{2}$ & catgaccaccatgaggata & gatagccacgagcatagtatt & (cca) 8 & $60^{\circ} \mathrm{C}$ \\
\hline
\end{tabular}

${ }^{1}$ Minamiyama et al. (2006); ${ }^{2}$ Lee et al. (2004); ${ }^{3}$ Geethanjali et al. (2010); ${ }^{4}$ Sanwen et al. (2000); ${ }^{5}$.S. Department of Agriculture (2011).

Tabela 3. Tamanho esperado do alelo em pares de base (TEA - pb), número de alelos por microssatélite (NAL), heterozigosidade esperada (He) e observada (Ho), coeficiente de informação polimórfica (PIC) e coeficiente de endogamia (f) (expected allele size, number of alleles per microsatellite locus, expected and observed heterozigosity, polymorphic information coefficient and endogamy coefficient). Campos dos Goytacazes, UENF, 2012.

\begin{tabular}{lllllll}
\hline SSR & TEA $(\mathbf{p b})$ & NAL & He & Ho & PIC & f \\
\hline CAMS 024 & 219 & 17 & 0,93 & 0,73 & 0,92 & 0,24 \\
CAMS 117 & 223 & 23 & 0,94 & 0,73 & 0,94 & 0,25 \\
CAMS 191 & 224 & 15 & 0,92 & 0,00 & 0,91 & 1,00 \\
CAMS 207-2 & 243 & 10 & 0,85 & 0,00 & 0,83 & 1,00 \\
CAMS 358 & 218 & 8 & 0,86 & 0,00 & 0,84 & 1,00 \\
CAMS 309 & 235 & 9 & 0,84 & 0,00 & 0,82 & 1,00 \\
CACCEL1i & 243 & 9 & 0,87 & 0,00 & 0,86 & 1,00 \\
SLM6 49 & 233 & 11 & 0,84 & 0,00 & 0,83 & 1,00 \\
CM 0011 & 116 & 11 & 0,89 & 0,05 & 0,87 & 0,95 \\
CA 514272 & 259 & 11 & 0,87 & 0,00 & 0,86 & 1,00 \\
CA 847580 & 197 & 9 & 0,83 & 0,13 & 0,81 & 0,85 \\
CA 523715 & 202 & 8 & 0,80 & 0,00 & 0,77 & 1,00 \\
CA 515649 & 190 & 6 & 0,79 & 0,00 & 0,75 & 1,00 \\
CM 0008 & 195 & 10 & 0,87 & 0,00 & 0,85 & 1,00 \\
CM 0005 & 160 & 10 & 0,87 & 0,00 & 0,86 & 1,00 \\
\hline Média & - & 12,5 & 0,92 & 0,11 & 0,92 & 0,89 \\
\hline
\end{tabular}

de informação de polimorfismo. Foi possível verificar que aproximadamente 53\% dos primers apresentaram valor de PIC superior à média geral. Isso nos permite, de acordo com a classificação de Botstein et al. (1980), afirmar que todos os marcadores utilizados no trabalho apresentam alta informação polimórfica. A porcentagem de primers em homozigose foi de $73 \%$ (11 primers); os demais $27 \%$ (4 primers) apresentaram valor entre 5 e $73 \%$ de heterozigosidade, sendo o valor de $73 \%$ originado dos primers CAMS 024 e CAMS 117. Verificou-se também que a taxa de endogamia foi de 24 e $25 \%$ respectivamente. Já os dois outros primers que também apresentaram valor de heterozigosidade acima de zero, apresentaram taxa de endogamia relativamente alta, 95\% (primer CM 011) e 85\% (primer CA 847580) 


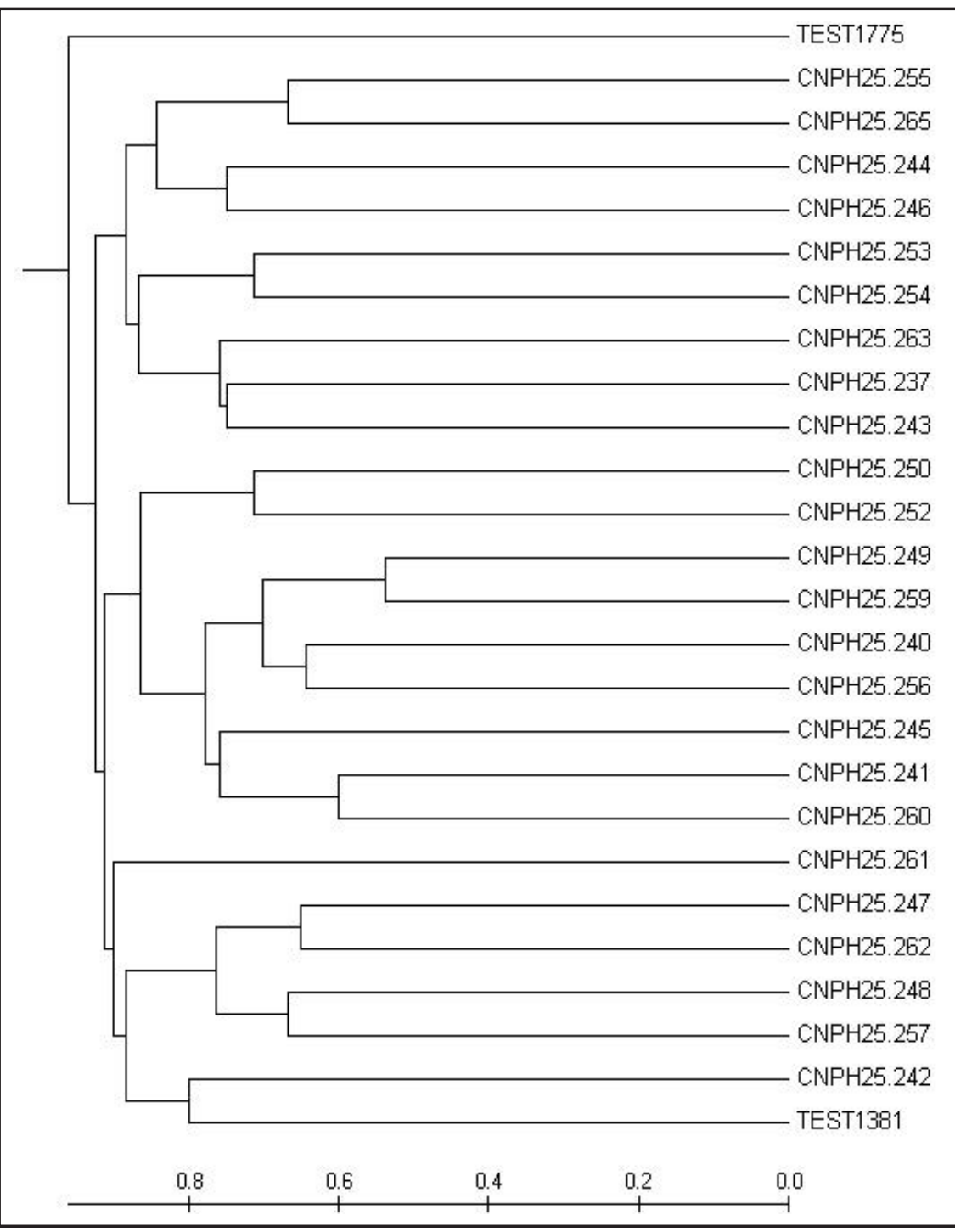

Figura 1. Dendrograma de dissimilaridade das 26 linhagens de Capsicum spp., obtido pelo método UPGMA. TEST1775 corresponde a uma pimenta do tipo Malagueta e TEST1381 a um pimentão (dissimilarity dendrogram for the 26 Capsicum inbred lines obtained by UPGMA. TEST1775 corresponds to a Malagueta pepper and TEST1381 to a sweet pepper). Campos dos Goytacazes, UENF, 2012.

respectivamente (Tabela 3). Esse alto valor de endogamia pode ser explicado pelo fato da população em estudo estar na $4^{\text {a }}$ geração $\left(\mathrm{S}_{4}\right)$ de autofecundação. Em uma população que se encontra em $\mathrm{S}_{4}$ verifica-se em média uma taxa de homozigose de $93,75 \%$. Isso é possível pois a cada geração de autofecundação espera-se ao menos $50 \%$ de endogamia nos seus descendentes.

A partir do padrão de bandas obtido com os 15 primers selecionados no estudo, obteve-se o dendrograma de dissimilaridade dos materiais (Figura 1). A comparação entre os materiais de Jalapeño amarelo e as duas testemunhas UENF 1381 e UENF 1775 (TEST 1381 e TEST 1775, respectivamente) sendo uma $C$. annuum do tipo pimentão e outra C. frutescens (pimenta malagueta), permite verificar que os materiais de Jalapeño amarelo possuem alta diversidade genética entre si $(0,9020)$, valor próximo do verificado quando o grupo é comparado a uma espécie diferente $(C$. frutescens, com valor de dissimilaridade 0,9607). A partir do dendrograma foram obtidos 4 grupos:

Grupo I - TEST1775;

Grupo II - CNPH 25.255, CNPH 25.252, CNPH 25.244, CNPH 25.246, CNPH 25.253, CNPH 25.254, CNPH 25.263, CNPH 25.237 e CNPH 25.243;
Grupo III - CNPH 25.250, CNPH.25.252, CNPH 25.249, CNPH 25.259, CNPH 25.240, CNPH 25.256, CNPH 25.245, CNPH 25.241 e CNPH 25.260;

Grupo IV - CNPH 25.261, CNPH 25.247, CNPH 25.262, CNPH 25.248, CNPH 25.257, CNPH 25.242 e TEST1381.

O primeiro grupo é formado pela testemunha referente a uma pimenta do tipo malagueta; os demais grupos formados são oriundos da população de Jalapeño amarelo. A formação desses três grupos dentro dessa população poderia sugerir que os grupos foram formados de acordo com cada fruto dos três que originaram a população do trabalho. Entretanto, foi verificado que esses três grupos não demonstraram relação alguma com os três frutos que deram origem aos genótipos avaliados, o que já era esperado, visto que as três plantas originais correspondiam ao mesmo material comercial híbrido (Jalapeño Plus $\mathrm{F}_{1}$ ).

\section{AGRADECIMENTOS}

Os autores agradecem as bolsas de pesquisa concedidas pela CAPES e pelo CNPq.

\section{REFERÊNCIAS}

BOTSTEIN D; WHITE RL; SKOLMICK H. 1980. Construction of a genetic linkage map in man using restriction fragment length polymorphism. American Journal of Human Genetics 32: 314-331.

BRASILEIRO ACM; CARNEIRO VTC. 1998. Manual de transformação genética de plantas. Brasília: Embrapa-SPI/Embrapa-Cenargen.

CARVALHO SIC; BIANCHETTI LB; RIBEIRO CSC; LOPES CA. 2006. Pimentas do gênero Capsicum no Brasil. Brasília: Embrapa Hortaliças. 15p.

GEETHANJALI S; CHEN KY; PASTRANA DV; WANG JF. 2010. Development and characterization of tomato SSR markers from genomic sequences of anchored BAC clones on chromosome 6 Euphytica 173: 85-97.

HANÁCEK P; VYHNÁNEK T; ROHRER M; CIESLAROVÁ J; STAVELÍKOVÁ H. 2009. DNA polymorphism in genetic resources of red pepper using microsatellite markers. Horticultural Science 36: 127-132.

HURTADO-HERNANDEZ H; SMITH PG. 1985. Inheritance of mature fruit color in Capsicum annuит L. J Hered. 76: 211-213.

KWON YS; LEE JM; YI GB; YI SI; KIM KM; 
SOH EH; BAE KM; PARK EK; SONG IH; KIM BD 2005. Use of SSR markers to complement tests of distinctiveness, uniformity, and stability (DUS) of pepper (Capsicum annuum L.) varieties. Molecules and Cells 19: 1-1.

LEE JM; NAHM SH; KIM YM; KIM BD 2004. Characterization and molecular genetic mapping of microsatellite loci in pepper. Theor Appl Genet 108: 619-627.

LIU J. 2004. Programa PowerMarker (versão 3.25). Disponível em http://www.powermarker.net

MINAMIYAMA Y; TSURO M; HIRAI M. 2006. An SSR-based linkage map of Capsicum annuиm. Mol Breeding 18: 157-169.

RODERIC DM. 2001. Programa TreeView (versão 1.6.6). Disponível em http://taxonomy. zoology.gla.ac.uk/rod/rodhtml

SANWEN H; BAOXI Z; MILBOURNE D; CARDLE L; GUIMEI Y; JIAZ-HEN G. 2000. Development of pepper SSR marker from sequence databases. Euphytica 117: 163-167.

USDA - United States Department of Agriculture. 2011. Sol Gennomics Network. Disponível em http://solgenomics.net/ 